\title{
ENHANCING THE MECHANICAL AND MICRO- STRUCTURAL PROPERTIES OF SILICA FUME BLENDED FLY ASH BASED GEOPOLYMER USING MURRAM AS A TERTIARY SUPPLEMENT
}

\author{
Debabrata Dutta ${ }^{1, *}$ and Somnath Ghosh ${ }^{2}$ \\ ${ }^{1}$ Research Scholar, Department of Civil Engineering, Jadavpur University, 188, Raja S. C. \\ Mallick Road, Kolkata-700032, India \\ ${ }^{2}$ Professor, Department of Civil Engineering, Jadavpur University, 188, Raja S. C. Mallick Road, \\ Kolkata-700032, India \\ *E-mail: ddebabrata83@gmail.com
}

\begin{abstract}
The present study aims to investigate the compressive strength and the underlying micro-structural change of fly ash geopolymer paste with silica fume and murram as supplements up to $10 \%$ and $2.5 \%$ of the total weight respectively. The workability property of the geopolymer paste samples was evaluated at a green state using a unique methodology based on the polar graph. Besides, various geopolymer paste samples were subjected to heat curing at different temperatures and also for different durations to find the influence of heat curing to the obtained compressive strengths. The present study also probed into the underlying micro-structural changes of the corresponding geopolymer paste samples through SEM (Scanning Electron Microscopy), MIP (Mercury Intrusion Porosimetry) and EDX (Energy Dispersive X-Ray Analysis). Through the present analysis, it can be concluded that blending of silica fume and murram with fly ash based geopolymer paste results in a sustainable high performance binder even at lower alkalinity with lower heat consumption as well as lower water content which can be considered as a better alternative of cement concrete binder to march towards environmental sustainability.
\end{abstract}

Keywords: Geopolymer, Fly ash, Silica fume, Murram, Strength, Micro-structure, High Performance.

(C) RASĀYAN. All rights reserved

\section{INTRODUCTION}

Ordinary Portland cement (OPC) is continuing to be used as an indispensable building material for decades. However, the production of OPC is associated with a lot of energy consumption and is a significant contributor towards the huge amount of greenhouse gases emissions triggering the threat of global warming ${ }^{1}$. Cement industry produces a huge amount of carbon dioxide in the atmosphere ${ }^{2}$. With growing environmental consciousness, there is a renewed interest among the environmentalists to reduce the effluence of cement and others industry as much as possible which enforced the material scientists to look for greener alternatives ${ }^{3}$. Beside this, the sustainable performance of Portland cement is another major limitations ${ }^{4}$. Recently, geopolymers have been investigated extensively as an alternative binder with a view to producing green, durable and sustainable concretes ${ }^{5,6}$. Various alternative cementitious materials (like fly ash, slag, metakaoline and others) are found to have potential application to resolve the durability aspects of cement concrete ${ }^{7}$. Again, an enormous surplus of fly ash all over the world has also boosted its usage to produce alternative binders ${ }^{8}$.

Principally, geopolymer, a novel inorganic polymer binding material, is prepared by the activation of base material consisting silica and alumina like fly ash in presence of strong alkali like sodium hydroxide and sodium silicate resulting in a three-dimensional amorphous aluminosilicate network with better binding properties $^{9-11}$.

Rasayan J. Chem., 11(3), 1018-1033(2018)

http://dx.doi.org/10.31788/RJC.2018.1133046

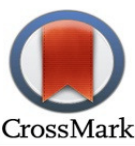


Fly ash is amorphous spherical particles. But the content of fly ash usually varies with the types of coal and plants ${ }^{9}$. Geopolymer based on fly ash, may be utilized as a binder instead of cement to mix with aggregates in a manner to form geopolymer concrete. Performance of geopolymer is proved better than cement in different aspects like high early strength, resistance to chemical attack and higher compressive strength etc. ${ }^{9-11}$. Substantial studies are already available on fly ash based geopolymer concrete ${ }^{9-12}$. Recently a few important studies have been focused on blended geopolymer to meet advanced properties of $\mathrm{it}^{42}$.

Silica fume, a secondary sequel in the production of silicon amalgams, is treated as highly reactive pozzolana and is widely used in conventional concrete to enhance its various strength and durability properties ${ }^{17}$. The basic fundamental cause of using siliceous mineral in conventional concrete is to emphasize secondary CSH formation ${ }^{18}$. Geopolymers was announced as an amorphous three-dimensional aluminosilicate binder material by Davidovits ${ }^{19}$. Combative materials like fly ash consisting of silica and alumina are quickly disbanded into the strong alkaline solution to make liberated silico-aluminate tetrahedral components. These tetrahedral units are linked through a rotator mode to reach into amorphous geopolymers during the poly-condensation reaction ${ }^{19-20}$. In alkalinity, the base material dissolves progressively to form oligomers; then precipitation of geopolymers are formed. Nevertheless, a very rare study on fume silica in geopolymer is available in the existing literature. Limited works have focussed on studying the performance of silica fume blended fly ash based geopolymer concrete ${ }^{13-16}$. Chindaprasirt et al. concluded that silica fume as supplements improves the performance of fly ash geopolymer in connection with strength and durability ${ }^{13}$. Lee et al. have shown that the reactivity of geopolymer concrete is enhanced when a combination of fly ash, slag, and silica fume is used as binder ${ }^{14}$. Okoye et al. have recently reported that fume silica in fly ash geopolymer improves the physical performance ${ }^{15}$. Very recently, Duan et al. investigated the performance of silica fume blended activated fly ash in micro and macro level after temperature fluctuating cycles with different heating temperatures of $200^{\circ} \mathrm{C} ; 400^{\circ} \mathrm{C}$ and $800^{\circ} \mathrm{C}$, replacing fly ash by $0 \%$ to $30 \%$ silica fume with an interval of $10 \%$, by weight ${ }^{16}$. They commented that blended geopolymer emphasizes rapid strength development in geopolymer.

A few recent studies have reported the diverse effect of silica fume on the consistency of geopolymer which in fact marginalize the massive usage of this composite indeed. Also, the maximum strength of silica fume based geopolymer is dropped remarkably under thermal fluctuation but this drop after thermal cycles is independent of silica fume content ${ }^{16}$. Therefore, there is a need to explore the possibilities of other contentious materials like murram (having similar property as red mud) to be blended together with fumed silica in the geopolymer with FA as a base material, to cut off the limitations. The advantageous part is that murram and fly ash is environmentally safe. Moreover, these materials can be procured free of cost in India. Few studies have investigated the potential of red mud to be used in geopolymer concrete. Kumar et al. used Red Mud and Fly ash in Geopolymer for developing a paving block and showed that incorporation of supplements effects on the better reaction rate and hardened properties of the blended geopolymer; 5-20\% red mud is found to be optimum in the improvement in setting time and compressive strength ${ }^{21}$. Ye et al. applied a thermal pre-treatment to correlate it with the dissolution of supplements and its rate of geopolymerisation ${ }^{22}$. This research found the effect of red mud to reduce the adverse effect of iron in alkaline solution. Again this study was focused on the transformation of phase in the midst of thermal treatment. Zhang et al investigated the various properties in micro and macro level for the red mud blended geopolymer with varying composition of the material and curing pattern ${ }^{23}$. They found that an increase in geopolymer strength with increasing $\mathrm{Si} / \mathrm{Al}$ and $\mathrm{Na} / \mathrm{Al}$ ratios up to 25 weeks.

In natural clay material, the approach of aluminosilicate is governed by calcination. Calcination is a thermal healing process in presence of oxygen applied to ores, to bring about a thermal decomposition, phase transition or removal of a volatile fraction ${ }^{24}$. This formation is projected through three steps: firstly; construction of a gas, secondly; improvement in viscous nature thirdly; progressive association. These steps execute three basic occurrences like (a) production of di-hydrogen (b) silicon oxidation (c) development of silicon hydride class as demonstrated earlier ${ }^{25}$.

The chemistry states that excessive presence of reactive silica may cause porous character by the generation of hydrogen ${ }^{26}$. Contributions of various ingredients in alkali-activated fly ash based geopolymer are needed to be discussed. In activation of fly ash, the pozzolana freely dilutes in alkali and consequently emphasizes geopolymerisation ${ }^{19}$. 
RASĀYAN J. Chem.

Vol. 11 | No. 3 |1018 - 1033 | July - September | 2018

$\mathrm{Si}^{0} \rightarrow \mathrm{Si}^{4+}+4 \mathrm{e}^{-}$

$4 \mathrm{H}_{2} \mathrm{O}+4 \mathrm{e}^{-} \rightarrow 2 \mathrm{H}_{2}+4 \mathrm{OH}^{-}$

$4 \mathrm{H}_{2} \mathrm{O}+\mathrm{Si}^{0} \rightarrow 2 \mathrm{H}_{2}+\mathrm{Si}(\mathrm{OH})_{4}$

Alkali metal hydroxide contributes to the cations ( $\mathrm{Na}, \mathrm{K}, \mathrm{Ca}$ and other metallic cations) which are required to maintain the structure neutrality (as aluminium is of four-fold). The purpose of the alkali cations is to balance the extra ionic charges. Here the term structural neutrality implies neutralization of ionic charges. Reactive silica-alumina in the alkaline medium cannot produce geopolymer unless it is introduced with heat. Investigations of Kirschner et al. elaborate that geopolymer formation in room temperature is not feasible ${ }^{27}$.

The research was designed to develop blended fly ash based geopolymer paste, keeping the following parameter as targets.

1. Geopolymer strengthening at low Alkalinity $\left(<8 \% \mathrm{~K}_{2} \mathrm{O}\right.$ of total base particles)

2. Geopolymer strengthening at low Silicate Modulus $(<1.0)$

3. Geopolymer workability at low water content $(<0: 33=$ Water/Fly Ash)

4. Geopolymer strengthening at a low temperature of heat curing $\left(<85^{\circ} \mathrm{C}\right)$

5. Geopolymer strengthening at less curing duration $(<48 \mathrm{Hrs})$

The replacement of traditional construction materials by new materials like geopolymer has already risen. Most of the studies were carried out to compare the geopolymer with the conventional construction material. Recently research has been employed to the properties blended fly ash geopolymer. The combinational study is essential to develop advanced geopolymer products that consume less alkali and heat energy in preparation. The study deals with blended geopolymer with better workability, strength, and microstructure which require less alkali and heat for preparation. The study will be effective to the production of cost-effective geopolymer as non-conventional sustainable material in concrete industry. These materials are very much novel with substantial potential to be used as commercially.

\section{EXPERIMENTAL}

Present research elaborately represents comprehensive results of 14 different laboratory trial mixes. An extensive parametric study has been carried out considering the strength of the alkaline solution, the water content in the mixture, base material, supplementary material, heat curing profile. Moreover, the paste samples have been studied in plastic as well as the hardened state. Compressive Strength Test, Area Factor Test, MIP, SEM, and EDX have been carried out to evaluate the performance of various kinds of geopolymer binder with a view to choosing an optimal mix design.

\section{Materials and Methods}

The chemical composition of the Fly Ash conforms to class F in accordance with ASTMC618 and was supplied by Kolaghat Thermal Power Plant, Murram were supplied by Ujjwal Chemical Works, Ranaghat, Kolkata, India and Silica Fume were supplied by Oriental Trexim Pvt. Ltd. The detail composition is reported in Table-1. The loss of ignition LOI is seen possibly due to the presence of hydrated compounds and residual organic matter. Scanning electron microscopy results of fly ash, murram and silica fume are given in Fig.-1. Different ranges of particle sizes are seen to be present in these three raw materials which are clearly observed from magnified pictures. The magnification had to varied for different samples to have a clear picture. In the case of murram, the magnification was kept less in comparison to others as its particle size was larger. However, it was higher for fly ash to pinpoint the fraction of very finer particles comprised with the larger particles.

More than $75 \%$ of grain size was less than $45 \mu$ with $380 \mathrm{~m}^{2} / \mathrm{Kg}$ as specific surface area. Fume silica of specific gravity of 2.36 and surface area (BET) of $8900 \mathrm{~m}^{2} / \mathrm{kg}$ was used. Typical values of murram were also accounted. It indicates that $85 \%$ of the volume was below $75 \mu \mathrm{m}$. The specific surface area (BET) of murram was $171 \mathrm{~m}^{2} / \mathrm{Kg} .85$ percent pure potassium hydroxide in pellet form and sodium silicate solution $\left(\mathrm{Na}_{2} \mathrm{O}, \mathrm{SiO}_{2}, \mathrm{H}_{2} \mathrm{O}\right.$ were $8 \%, 26.5 \%$, and $65.5 \%$ respectively). For the silicate solvent, silicate modulus and bulk density were kept 3.3 and $1410 \mathrm{~kg} / \mathrm{m}^{3}$ respectively. All the alkali solutions were brought from Loba 1020 
RASĀYAN $J$. Chem.

Vol. 11 | No. 3 |1018 - 1033 | July - September | 2018

Chemie Ltd, India. To prepare the alkaline activator solution, the required quantity of potassium hydroxide pellets was first dissolved directly into the water and was left at room temperature for 24 hours (shown in Fig.-2b).

\begin{tabular}{l|c|c|c|c|c|c|c|c|c|c|c}
\multicolumn{1}{c}{ Table-1: Chemical Analysis Report of Fly Ash, Silica Fume and Murram (In percentage) } \\
\hline \multicolumn{1}{c|}{ Materials } & $\mathrm{SiO}_{2}$ & $\mathrm{Al}_{2} \mathrm{O}_{3}$ & $\mathrm{Fe}_{2} \mathrm{O}_{3}$ & $\mathrm{TiO}_{2}$ & $\mathrm{CaO}$ & $\mathrm{MgO}$ & $\mathrm{K} 2 \mathrm{O}$ & $\mathrm{Na}_{2} \mathrm{O}$ & $\mathrm{SO}_{3}$ & $\mathrm{P}_{2} \mathrm{O}_{5}$ & LOI \\
\hline Fly Ash & 56.01 & 29.80 & 03.58 & 01.75 & 02.36 & 00.30 & 00.73 & 00.61 & 00.00 & 00.44 & 00.40 \\
\hline Silica Fume & 92.00 & 00.46 & 01.60 & 00.00 & 00.29 & 00.28 & 00.61 & 00.51 & 00.19 & 00.00 & 01.00 \\
\hline Murram & 21.06 & 26.01 & 13.02 & 04.21 & 17.12 & 02.22 & 02.04 & 05.30 & 00.00 & 00.00 & 09.02 \\
\hline
\end{tabular}
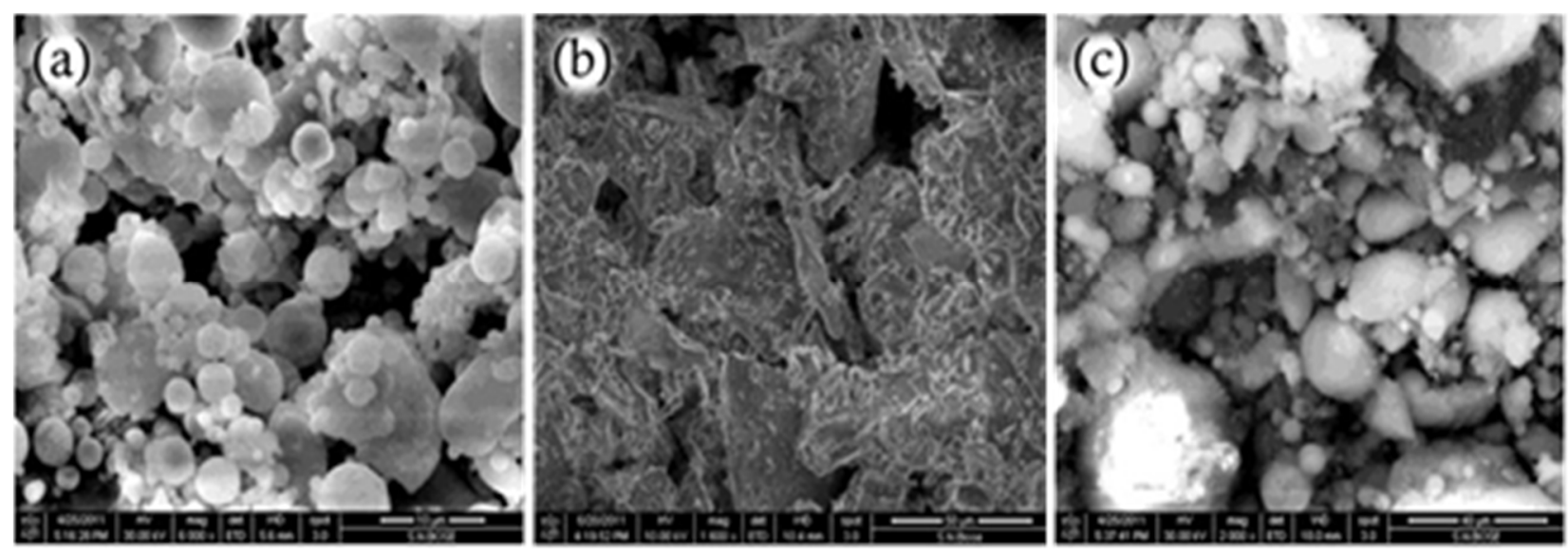

Fig.-1: SEM images of- (a) Fly ash, (b) Murram, (c) Silica Fume
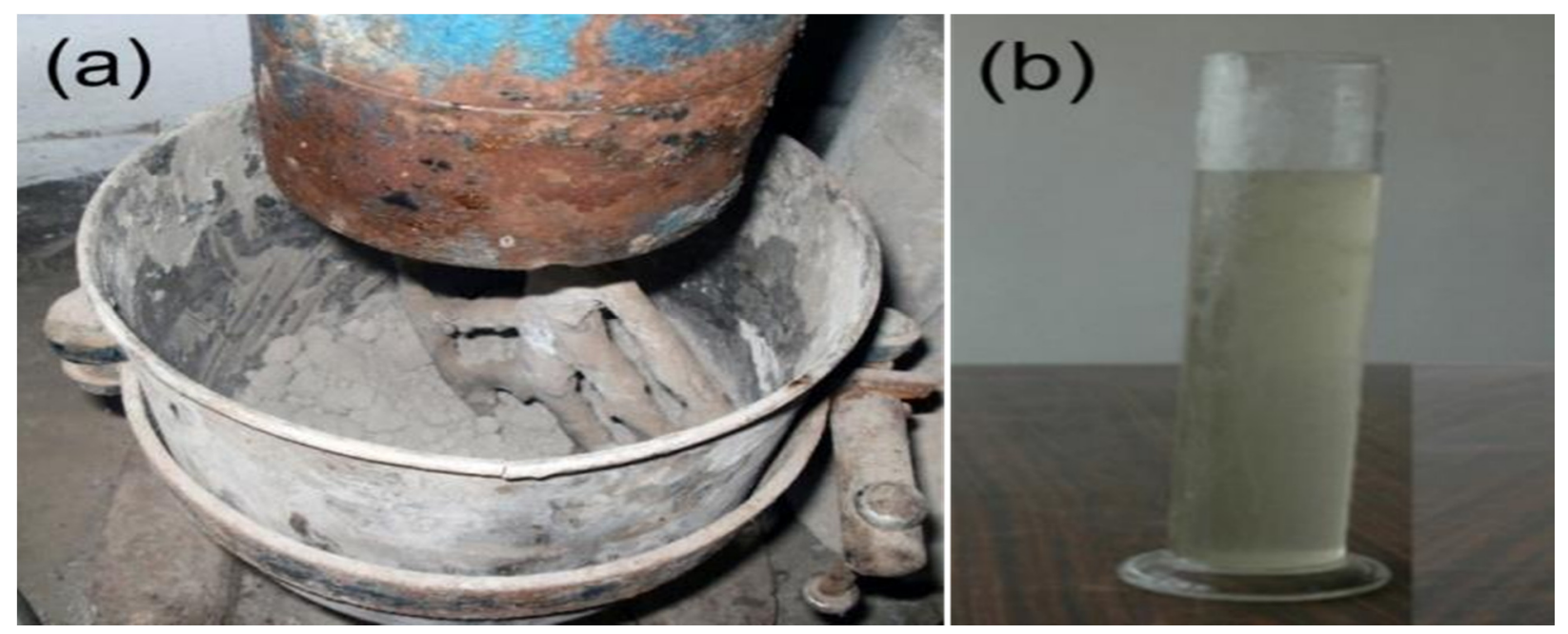

Fig.-2: (a) Hobart Mixture, (b) Alkaline activator

The silicate solution was mixed around three hours earlier the preparation of geopolymer pastes. Dissolution of potassium hydroxide pellets in water is an exothermic reaction. Hence, the generation of heat from the solution indicates the progress of the reaction. Although in the earlier study it is mentioned that one-night stay of the solution is sufficient ${ }^{28}$. A duration of $24 \mathrm{hrs}$ is kept constant for every case to be assured of the completion of the process. When the reaction of potassium hydroxide solution with sodium silicate is an exothermic reaction and takes few hours to get cool. However excessive time delay brings in white precipitation within the solution. So, $3 \mathrm{hrs}$. rest was optimized and made fixed in this research. These activator solutions had $\mathrm{K}_{2} \mathrm{O}$ content equal to either $6.0 \%$ or $8.0 \%$ of fly ash. $\mathrm{SiO}_{2} /\left(\mathrm{K}_{2} \mathrm{O}+\mathrm{Na}_{2} \mathrm{O}\right)$ ratio in 
RASĀYAN J. Chem.

Vol. 11 | No. 3 |1018 - 1033 | July - September | 2018

activator solution was maintained equal to either 0.0 or 0.77 . Sodium silicate was used as the source of $\mathrm{SiO}_{2}$ in activator solution. $\mathrm{SiO}_{2} / \mathrm{K}_{2} \mathrm{O}$ is the apparent silicate modulus. The Hobart mixture of model P660 of capacity $600 \mathrm{cc}$ and speed of $60 \mathrm{cps}$ was used for the mixing of paste. Mixing proportion of the geopolymer paste is specified in Table-2a.

Table-2a: Mix Proportion of Geopolymer Pastes

\begin{tabular}{|c|c|c|c|c|c|c|}
\hline $\begin{array}{c}\text { Sample } \\
\text { Id. }\end{array}$ & $\begin{array}{l}\text { Silica } \\
\text { Fume* }\end{array}$ & Murram* & $\begin{array}{c}\mathrm{K} 2 \mathrm{O} \text { in } \\
\text { activator* }\end{array}$ & $\begin{array}{c}\mathrm{SiO} 2 \text { in } \\
\text { activator* }\end{array}$ & $\begin{array}{l}\mathrm{SiO} 2 / \mathrm{K} 2 \mathrm{O} \\
\text { in activator }\end{array}$ & Water* \\
\hline GPK1 & $0.0 \%$ & $0.0 \%$ & $8 \%$ & $8 \%$ & 1.0 & $33 \%$ \\
\hline GPK2 & $0.0 \%$ & $0.0 \%$ & $8 \%$ & $0 \%$ & 0.0 & $33 \%$ \\
\hline GPK3 & $0.0 \%$ & $0.0 \%$ & $6 \%$ & $6 \%$ & 1.0 & $33 \%$ \\
\hline GPK4 & $0.0 \%$ & $0.0 \%$ & $6 \%$ & $0 \%$ & 0.0 & $33 \%$ \\
\hline GPK5 & $10 \%$ & $0.0 \%$ & $8 \%$ & $8 \%$ & 1.0 & $33 \%$ \\
\hline GPK6 & $10 \%$ & $0.0 \%$ & $8 \%$ & $0 \%$ & 0.0 & $33 \%$ \\
\hline GPK7 & $10 \%$ & $0.0 \%$ & $6 \%$ & $6 \%$ & 1.0 & $33 \%$ \\
\hline GPK8 & $10 \%$ & $0.0 \%$ & $6 \%$ & $0 \%$ & 0.0 & $33 \%$ \\
\hline GPK9 & $10 \%$ & $2.5 \%$ & $8 \%$ & $8 \%$ & 1.0 & $33 \%$ \\
\hline GPK10 & $10 \%$ & $2.5 \%$ & $8 \%$ & $0 \%$ & 0.0 & $33 \%$ \\
\hline GPK11 & $10 \%$ & $2.5 \%$ & $6 \%$ & $6 \%$ & 1.0 & $33 \%$ \\
\hline GPK12 & $10 \%$ & $2.5 \%$ & $6 \%$ & $0 \%$ & 0.0 & $33 \%$ \\
\hline GPK13 & $10 \%$ & $2.5 \%$ & $8 \%$ & $8 \%$ & 1.0 & $25 \%$ \\
\hline GPK14 & $10 \%$ & $2.5 \%$ & $6 \%$ & $6 \%$ & 1.0 & $25 \%$ \\
\hline
\end{tabular}

*\% of (fly ash + silica fume+ murram) in weight

The typical mix composition for $1000 \mathrm{gm}$. of the base material (fly ash + silica fume + murram) is given in Table-2b. Here in this research, the $\mathrm{K}_{2} \mathrm{O} \%$ with respect to (fly ash + silica fume + murram) in weight and the apparent silicate modulus $\left(\mathrm{SiO}_{2} / \mathrm{K}_{2} \mathrm{O}\right)$ are taken as the input parameters of the mix. The actual silicate modulus or solution modulus is calculated from $\mathrm{SiO}_{2} /\left(\mathrm{K}_{2} \mathrm{O}+\mathrm{Na}_{2} \mathrm{O}\right)$. The water content (as given in Table2c) is total of $\mathrm{H}_{2} \mathrm{O}$ molecules coming from (i) $\mathrm{KOH}$ dissolution, (ii) water added for making $\mathrm{KOH}$ solution, (iii) Sodium silicate solution and (iv) additional water for mixing.

Table-2b: Sample Calculations of Different Mixes

\begin{tabular}{|c|c|c|c|c|c|c|c|c|c|c|c|}
\hline $\begin{array}{l}\text { Sample } \\
\text { Id }\end{array}$ & $\begin{array}{l}\text { Fly } \\
\text { Ash } \\
\text { (gm.) }\end{array}$ & $\begin{array}{l}\text { Silica } \\
\text { Fume } \\
\text { (gm.) }\end{array}$ & $\begin{array}{c}\text { Murram } \\
\text { (gm.) }\end{array}$ & $\begin{array}{r}\mathrm{K}_{2} \mathrm{O} \\
(\mathrm{gm} .)\end{array}$ & $\begin{array}{l}\text { Apparent } \\
\text { Silicate } \\
\text { modulus }\end{array}$ & $\begin{array}{l}\mathrm{SiO}_{2} \\
\text { (gm.) }\end{array}$ & $\begin{array}{c}\text { Sodium } \\
\text { Silicate } \\
(\mathrm{SS})(\mathrm{gm} .)\end{array}$ & $\begin{array}{c}\mathrm{Na}_{2} \mathrm{O} \\
\text { From } \\
(\mathrm{SS}) \\
\text { (gm.) }\end{array}$ & $\begin{array}{l}\mathrm{KOH} \\
\text { (gm.) }\end{array}$ & $\begin{array}{c}\text { Pure KOH } \\
\quad \text { (gm.) }\end{array}$ & $\begin{array}{l}\text { Silicate } \\
\text { Modulus }\end{array}$ \\
\hline GPK1 & 1000 & 0 & 0 & 80 & 1 & 80 & 301.89 & 24.24 & 95.30 & 109.60 & 0.77 \\
\hline GPK2 & 1000 & 0 & 0 & 80 & 0 & 0 & 0.00 & 0.00 & 95.30 & 109.60 & 0.00 \\
\hline GPK3 & 1000 & 0 & 0 & 60 & 1 & 60 & 226.42 & 18.18 & 71.48 & 82.20 & 0.77 \\
\hline GPK4 & 1000 & 0 & 0 & 60 & 0 & 0 & 0.00 & 0.00 & 71.48 & 82.20 & 0.00 \\
\hline GPK5 & 900 & 100 & 0 & 80 & 1 & 80 & 301.89 & 24.24 & 95.30 & 109.60 & 0.77 \\
\hline GPK6 & 900 & 100 & 0 & 80 & 0 & 0 & 0.00 & 0.00 & 95.30 & 109.60 & 0.00 \\
\hline GPK7 & 900 & 100 & 0 & 60 & 1 & 60 & 226.42 & 18.18 & 71.48 & 82.20 & 0.77 \\
\hline GPK8 & 900 & 100 & 0 & 60 & 0 & 0 & 0.00 & 0.00 & 71.48 & 82.20 & 0.00 \\
\hline GPK9 & 875 & 100 & 25 & 80 & 1 & 80 & 301.89 & 24.24 & 95.30 & 109.60 & 0.77 \\
\hline GPK10 & 875 & 100 & 25 & 80 & 0 & 0 & 0.00 & 0.00 & 95.30 & 109.60 & 0.00 \\
\hline
\end{tabular}


RASĀYAN $J$. Chem.

Vol. 11 | No. 3 |1018 - 1033 | July - September | 2018

\begin{tabular}{c|c|c|c|c|c|c|c|c|c|c|c}
\hline GPK11 & 875 & 100 & 25 & 60 & 1 & 60 & 226.42 & 18.18 & 71.48 & 82.20 & 0.77 \\
\hline GPK12 & 875 & 100 & 25 & 60 & 0 & 0 & 0.00 & 0.00 & 71.48 & 82.20 & 0.00 \\
\hline GPK13 & 875 & 100 & 25 & 80 & 1 & 80 & 301.89 & 24.24 & 95.30 & 109.60 & 0.77 \\
\hline GPK14 & 875 & 100 & 25 & 60 & 1 & 60 & 226.42 & 18.18 & 71.48 & 82.20 & 0.77 \\
\hline
\end{tabular}

Table-2c: Sample Calculation for water and density of mixes

\begin{tabular}{c|c|c|c|c|c|c|c|c}
\hline Sample Id & $\begin{array}{c}\text { Fly Ash } \\
\text { (gm.) }\end{array}$ & $\begin{array}{c}\text { Silica } \\
\text { Fume } \\
\text { (gm.) }\end{array}$ & $\begin{array}{c}\text { Murram } \\
\text { (gm.) }\end{array}$ & $\begin{array}{c}\text { Water From } \\
\text { (SS) }(\mathrm{gm} .)\end{array}$ & $\begin{array}{c}\text { Water From } \\
\text { KOH (gm.) }\end{array}$ & $\begin{array}{c}\text { Extra } \\
\text { Water } \\
\text { (gm.) }\end{array}$ & $\begin{array}{c}\text { Total } \\
\text { Water }\end{array}$ & $\begin{array}{c}\text { The density of } \\
\text { mix gm./cc }\end{array}$ \\
\hline GPK1 & 1000 & 0 & 0 & 197.74 & 15.32 & 116.94 & 330 & 2.46 \\
\hline GPK2 & 1000 & 0 & 0 & 0.00 & 15.32 & 314.68 & 330 & 2.12 \\
\hline GPK3 & 1000 & 0 & 0 & 148.30 & 11.49 & 170.21 & 330 & 2.37 \\
\hline GPK4 & 1000 & 0 & 0 & 0.00 & 11.49 & 318.51 & 330 & 2.12 \\
\hline GPK5 & 900 & 100 & 0 & 197.74 & 15.32 & 116.94 & 330 & 2.4 \\
\hline GPK6 & 900 & 100 & 0 & 0.00 & 15.32 & 314.68 & 330 & 2.07 \\
\hline GPK7 & 900 & 100 & 0 & 148.30 & 11.49 & 170.21 & 330 & 2.32 \\
\hline GPK8 & 900 & 100 & 0 & 0.00 & 11.49 & 318.51 & 330 & 2.07 \\
\hline GPK9 & 875 & 100 & 25 & 197.74 & 15.32 & 116.94 & 330 & 2.39 \\
\hline GPK10 & 875 & 100 & 25 & 0.00 & 15.32 & 314.68 & 330 & 2.07 \\
\hline GPK11 & 875 & 100 & 25 & 148.30 & 11.49 & 170.21 & 330 & 2.31 \\
\hline GPK12 & 875 & 100 & 25 & 0.00 & 11.49 & 318.51 & 330 & 2.06 \\
\hline GPK13 & 875 & 100 & 25 & 197.74 & 15.32 & 36.94 & 330 & 2.59 \\
\hline GPK14 & 875 & 100 & 25 & 148.30 & 11.49 & 90.21 & 330 & 2.49 \\
\hline
\end{tabular}

Paste sample was chosen to predict the properties of the binder itself. The incorporation of aggregates brings multi-phase in a composite like a geopolymer mortar or concrete. In this study, the paste is considered to compare the performance of binder at gel and hardening phase. Cubical $(50 \mathrm{~mm} \times 50 \mathrm{~mm} \times$ $50 \mathrm{~mm}$ ) geopolymer paste specimen were investigated for typical hardened properties.

\section{Detection of Various Constraints \\ Effect of Supplements on Alkali Hydroxide}

Strong alkali activated silicon $\&$ aluminium, present in the base material, is the main contributor to have a partially or totally compacted activated composite ${ }^{29}$. The requirement of sodium silicate to emphasize the initial polymerization may be reduced by the application of highly reactive silica source like silica fume ${ }^{30}$. In higher solution modulus $\mathrm{Na}+$ is less effective for the stabilization of larger oligomer which can be effectively stabilized by cation like $\mathrm{K}^{+}$having larger size ${ }^{31}$. Here the concentration of sodium silicate in the activator solution is indicated by the silicate modulus or solution modulus. Practical investigation depicts that, a combination of potassium hydroxide and sodium silicate show better performance at higher silicate modulus of activator. $\mathrm{SiO}_{2} /\left(\mathrm{K}_{2} \mathrm{O}+\mathrm{Na}_{2} \mathrm{O}\right)$ results better than $\mathrm{SiO}_{2} / \mathrm{Na}_{2} \mathrm{O}$ when both the value is kept one ${ }^{32}$. Addition of higher silicate solution increases larger silicate composed molecules which is better coordinated by potassium ions ${ }^{19}$.Thus, an extra source of silica accelerates the rate of geopolymerization. So, the effect of silica fume at different alkalinity can be monitored by changing the percentage of $\mathrm{K}_{2} \mathrm{O}$ in the activator.

\section{Effect of Supplements on Silicate Modulus}

The function of sodium silicate is to start the polymerization essentially in an earlier stage The condensation process in the dissolution of geopolymer follows two stages; one is fast while another is slow ${ }^{33}$. Again, the degree of aluminosilicate polymerization depends on the concentration of silicate solution ${ }^{34,35}$. E. Prud'homme et al. confirm the existence of "in situ inorganic foam" in the presence of silica fume as an 
external agent in TGA-MS ${ }^{25,26}$. Here also, the effect of silica fume as supplementary of silicate solution can be investigated.

\section{Effect of Supplements on Water Content}

The addition of silica fume in geopolymer mixture enhances di-hydrogen due to oxidation of free silicon in the alkaline medium during synthesis ${ }^{25}$. The favourable effect in workability has already been established in literature $^{36}$. Higher consistency was expected even at lower water content in presence of silica fume. The change in consistency may be quantified in this study by using the typical polar chart as workability setup.

\section{Effect of Supplements on Curing Temperature}

The polymeric reaction is emphasized in high-temperature curing ${ }^{37}$. Low temperature or ambient temperature curing for geopolymer exhibits poor structure formation due to delayed setting ${ }^{27}$. The viscosity of geopolymer mixture is in fact increased with the rise in curing temperature ${ }^{2627}$. All of the aspects like the viscosity of gel, the polarity of gel, stabilization of geopolymer, production of binder product is emphasized by the higher rate of reaction which is a function of curing temperature. The presence of highly reactive silica from silica fume, which is not segregated like kaolinite causes highly soluble and reactive geopolymer system. Here the term segregation refers isolation of nonreactive particles under alkali activation which is largely present in kaolinite. The effect of silica fume on the curing temperature can be further studied to gain more insights behind the previous hypothesis.

\section{Effect of Supplements on Curing Duration}

A critical review of existing Literature depicts that increasing curing time improves the polymerization process by maintaining the dissolution of reactive species. Curing of geopolymer at high temperature for a longer period provides lower compressive strength. It is because of the breaking of the granular structure in geopolymer. Again, excessive dehydration and shrinkage affect in the same way ${ }^{26}$. Addition of more reactive silica fume in fly ash geopolymer may enhance amorphous to the semi-crystalline structure. While this semi-crystalline structure gets more affected by longer curing time ${ }^{38}$. The duration of curing time may be optimized with additional silica fume.

\section{Detection Method}

\section{Workability at Green State}

At the green level, the geopolymer gel was subjected to workability test. The workability was determined by a typical experimental setup. A polar chart was used. Fifty concentric circles and 40 radial lines were present in the chart. Smaller areal segments were best fitted to measure the slump. Every $\mathrm{n}^{\text {th }}$ circle confirms diameter of $\mathrm{n} \mathrm{cm}$. Typical brush cylinder $(6 \mathrm{~cm}$ diameter, $8 \mathrm{~cm}$ height) and a circular glass slab were used. The thickness and diameter of the glass slab were $7 \mathrm{~mm}$ and $50 \mathrm{~cm}$ respectively (as shown in the Fig.-3a).

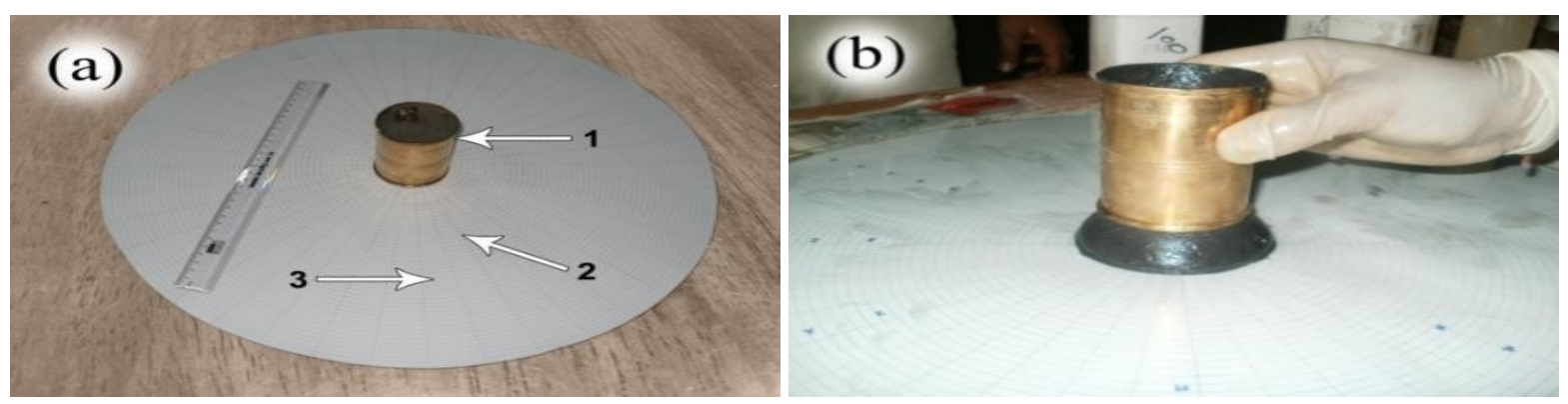

1. Brass cylinder 2. Polar chart 3. Circular shaped glass

Fig.-3: (a) Workability set up, (b) Raising of the cylinder

The polar graph was placed below the glass slab. Then brass cylinder was placed confirming that the centers of cylinder and slab coincide. The brass cylinder was used to hold the paste sample. The mold was filled by the paste sample immediately after 10 mints revolution in Hobart mixture. After one minute of 
detention period, the cylinder was elevated to permit the flow of the paste. After a certain time of flow ( $>1$ minute), reading corresponding to the outer most periphery of the flow was taken. The change in the rate of poly-condensation is reflected in the workability. Workability was expressed by the term Area factor. Where "Area Factor" represents the ratio of the area of unconfined paste to that of confined paste. This typical workability measurement procedure was implemented to find the spread of geopolymer paste in our earlier work ${ }^{31}$.

\section{Compressive strength at hardened state}

Compressive strength test of the specimen was tested by digital compression testing machine of model no. EM500 supplied by ENKAY Enterprise. The least count was $0.001 \mathrm{KN}$. The direct strength of hardened samples was determined after 3 days along with 28 days in a $2000 \mathrm{kN}$ capacity compression testing machine(digital ${ }^{39}$. The cube strength was determined as per ASTM C109. In each case, three or more than three identical specimens were measured as per ASTM C-109-02, average data were taken as strength.

\section{Microstructure characteristics by SEM and EDX analysis}

QUANTA 2000 of capacity $2.4 \mathrm{~nm}$ at $30 \mathrm{kv}$ at high vacuum condition was used to find the surface texture and internal morphology. Energy Dispersive X-Ray Analysis (EDX analysis) by ED spectrometer was conducted to find typical elemental configuration. At the time of crushing the samples were collected in a form of chips. The factor like an age for each sample was kept fixed so as to remove the concern like the effect of time on surface texture. The size of the samples was kept at about 5-8 $\mathrm{mm}$ in size. The dimension of any sample did not exceed $8 \mathrm{~mm}$.

\section{Pore morphology by MIP analysis}

Mercury Intrusion Porosimetry (MIP) was done to evaluate the PSD distribution curve for permeable pores in the form of pore volume versus apparent pore entry radius. The detail features are briefed in Table$2 \mathrm{~d}$. MIP was used to examine a numerical link between pore size, distribution and its total volume. Again it also determines the bulk density and apparent porosity at the same time. The intrusion pressure was moved up to 53500 psi for this case. In this method mercury is intruded under pressure in an evacuated sample and volume of intruded mercury is monitored against pressure. Mercury being a non-wetting liquid for most of the solids (especially for cement-based materials and ceramics), the intrusion process follows Washburn's equation that relates pressure to equivalent pore entry radius. Thus radius versus intruded volume curves can be obtained. In this test, $\mathrm{t} h \mathrm{e}$ distribution function specifies the portion in a function of any range of pore sizes which in fact yield volume of the pores within those assortments.

\section{Workability}

\section{RESULTS AND DISCUSSION}

Mobility or consistency is desired only with good strength characteristics. A sample having higher fluidity is not treated as favorable until it provides good enough strength characteristics. In conventional cement concrete, the basic feature at green state is controlled by water/cement ratio and water implies the added free water. To maintain the different mode of operation workability is tuned according to an appropriate mix design to obtain the desired compressive strength. Contrastingly, for geopolymer paste, the scenario is quite different as in this case, the raw materials contain a good amount of water content. Besides the progress of oxidation of Silicon di-hydrogen, more water is accumulated later on. Therefore, consistency is a function of the degree of reaction in the right mode.

Table-2d: Typical Setup of Quantachrome Poremaster and Sample Style

\begin{tabular}{c|c}
\hline Set up Name & Micromeritics Autopore II \\
\hline Set up Position & CGCRI, Kolkata \\
\hline Pressure Range & $0-60,000 \mathrm{pis}$ \\
\hline Hg Surface Tension & $480.00 \mathrm{erg} / \mathrm{cm}^{2}$ \\
\hline Minimum Delta Vol. & $0.000 \% \mathrm{FS}$ \\
\hline
\end{tabular}


RASĀYAN J. Chem.

Vol. 11 | No. 3 |1018 - 1033 | July - September | 2018

\begin{tabular}{c|c}
\hline Hg Contact Angle & (I) $140.00^{0},(\mathrm{E}) 140.00^{0}$ \\
\hline Moving Point Average & 11 (Scan Mode). Mercury volume normalized by sample weight \\
\hline Operating Software & Quantachrome poremaster for Windows Data Report version 7.01 \\
\hline Sample Size & $1 / 4$ inch diameter and $1 / 2$ inch height \\
\hline Bulk Sample Volume: & $1.0000 \mathrm{cc}$ \\
\hline
\end{tabular}

Table-3: Consistency Test Reports of Geopolymer at Green State.

\begin{tabular}{c|c|c|c|c|c}
\hline $\begin{array}{c}\text { Specimen } \\
\text { Id }\end{array}$ & $\begin{array}{c}\text { Primary Diameter } \\
(\mathrm{D} 1)(\mathrm{cm})\end{array}$ & $\begin{array}{c}\text { Ultimate } \\
\text { Equivalent Diameter } \\
(\mathrm{D} 2)(\mathrm{cm})\end{array}$ & $\begin{array}{c}\text { Primary } \\
\text { Area }(\mathrm{A} 1) \\
\left(\mathrm{cm}^{2}\right)\end{array}$ & $\begin{array}{c}\text { Ultimate Area } \\
\text { After Flow (A2) } \\
\left(\mathrm{cm}^{2}\right)\end{array}$ & $\begin{array}{c}\text { Area Factor } \\
=\mathrm{A} 2 / \mathrm{A} 1\end{array}$ \\
\hline GPK1 & 6 & 24 & 28.26 & 452.16 & 16.0 \\
\hline GPK2 & 6 & 6 & 28.26 & 28.26 & 1.0 \\
\hline GPK3 & 6 & 20 & 28.26 & 314 & 11.1 \\
\hline GPK4 & - & - & - & - & - \\
\hline GPK5 & 6 & 36 & 28.26 & 1017.36 & 36.0 \\
\hline GPK6 & 6 & 15 & 28.26 & 176.63 & 6.25 \\
\hline GPK7 & 6 & 33 & 28.26 & 854.87 & 30.3 \\
\hline GPK8 & 6 & 11 & 28.26 & 95 & 3.4 \\
\hline GPK9 & 6 & 34 & 28.26 & 907.46 & 26.1 \\
\hline GPK10 & 6 & 31 & 28.26 & 754.39 & 25.0 \\
\hline GPK11 & 6 & 30 & 28.26 & 706.5 & 20.3 \\
\hline GPK12 & 6 & 27 & 28.26 & 572.265 & 21.8 \\
\hline GPK13 & 6 & 28 & 28.26 & 615.44 & 26.7 \\
\hline GPK14 & 6 & 31 & 28.26 & 754.385 & \\
\hline
\end{tabular}

14 individual samples had a typical level of expansion or flow as reported in Table-3. As stated already that alkali cations play a major role for charge compensation of alumina which emphasis the polycondensation. The consistency of GPK3 was drastically changed from GPK1 as GPK3 had less KOH content. As explained earlier, sodium silicate initiates the polymerization. Sample GPK2 and GPK4 had slight to no plasticity after mixing (as shown in Fig.-3g) due to the absence of Sodium Silicate. Sample GPK5 and GPK7 had higher consistency. It is because of the faster formation of Si-O-Si in the presence of excessive reactive silica. Insufficient alumina is not desirable for the framework structure (tetrahedral) formation which causes weak bonding after curing. This problem can be compensated with the application of external alumina or its equivalent. Appreciable consistency with enhanced structure was obtained for sample GPK9 to sample GPK14. Sample GPK9, GPK10, GPK11 and GPK12 have better consistency in compare to GPK1, GPK2, GPK3 and GPK4 respectively. Most significant observation is that the sample GPK13 and GPK14 have better consistency even at low water content in comparison to that of GPK1 and GPK3.

\section{Compressive Strength}

Twenty cubical $(50 \mathrm{~mm} \times 50 \mathrm{~mm} \times 50 \mathrm{~mm})$ samples from each series were considered for strength testing. Mean compressive strength value is stated in Table- 4 . The compressive strengths of paste samples, cured at $85^{0}$ for 48 hours, are given in the first column of Table- 4 . The silica fume addition (by $10 \%$ of total weight) in the presence of murram (2.5\% by total weight) gave a better result for every case. Typical volumetric increment (as shown in Fig.-5a) was noticed for Sample GPK5 and GPK7. It may be because of the formation of chain structure instead of frame work structure. Sample GPK5 and GPK7 were not appropriate for testing strength. The geometry of cured GPK5 and GPK7 samples (as shown in Fig.-4a) were not perfect for the compressive strength test. This volumetric increment was reduced by the application of $2.5 \%$ murram (by total weight). The replacement of fly ash by a certain amount of silica fume and murram gave a favorable increment of compressive strength. Sample GPK9 showed around 26.25\% 
increment from GPK1 and Sample GPK11 showed around 58.03\% increment from GPK3. Interestingly sample GPK2 and GPK4 had the poor result in absence of sodium silicate solution which allows the primary geopolymerisation as discussed earlier. But GPK10 and GPK12 showed better result even at zero sodium silicate. This result supports that silica fume acted as a partial compensator of sodium silicate solution. As mentioned earlier, external reactive silica emphasizes the oxidation which causes the continuous production of the di-hydrogen at the time of mixing. Due to this fact appropriate consistency was available for sample GPK13 and GPK14 at lower water content. The reduction of excess water (8\% drop in water content) gave $14.55 \%$ and $20.91 \%$ increment in compressive strength from sample GPK9 and GPK11 respectively.
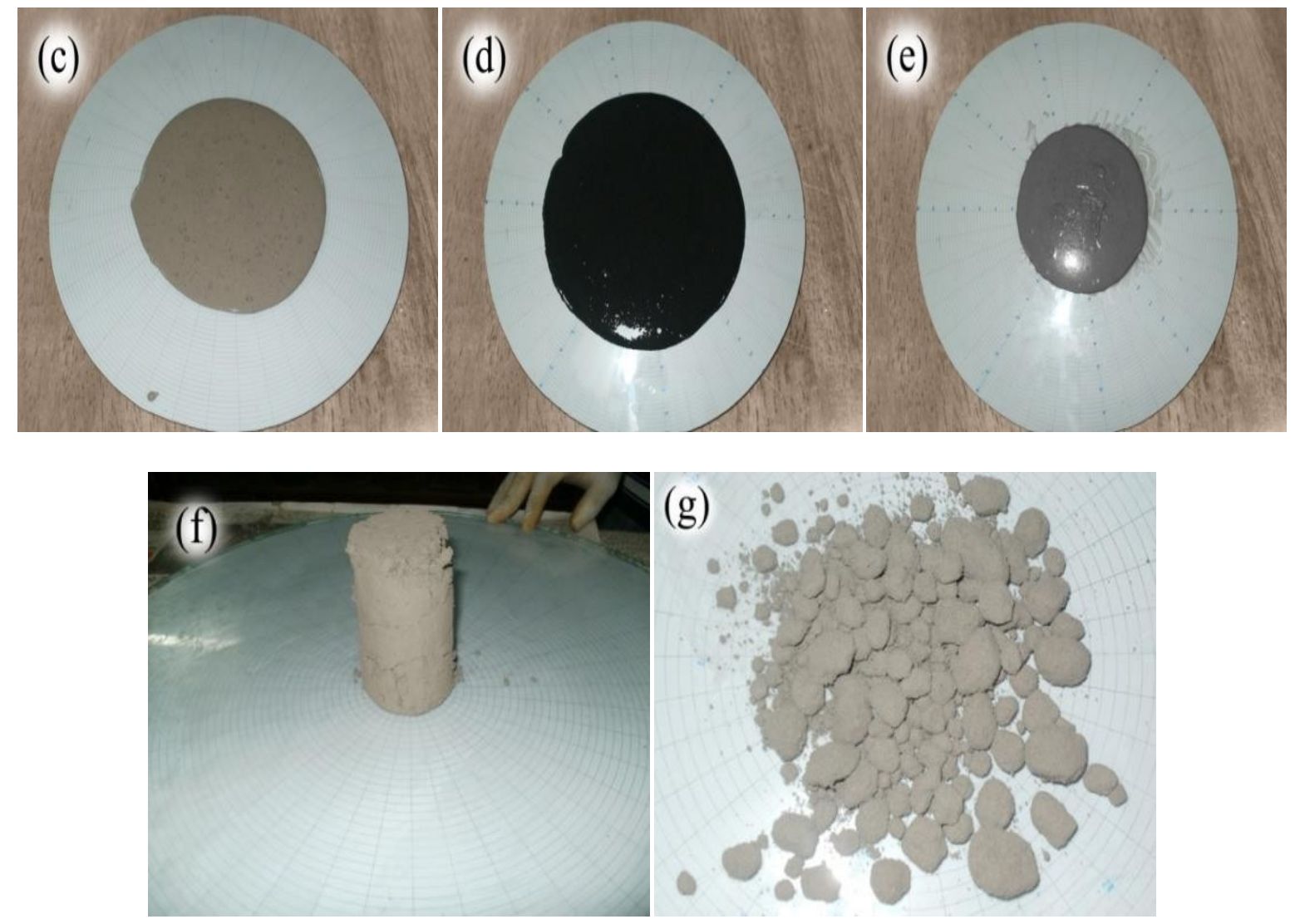

Fig.-3: (c) Sample GPK1, (d) Sample GPK10, (e) Sample GPK3, (f) Sample GPK2, (g) Sample GPK4

Reduction in curing temperature and duration had an adverse effect for every case. The drop in compressive strength for sample GPK9, GPK11, GPK13, and GPK14 were minimum. Due to the reduction in curing temperature from $85^{\circ} \mathrm{C}$ to $55^{\circ} \mathrm{C}$, the compressive strength was seen to drop by $7.6 \%$ and $8.03 \%$ for sample GPK13 and GPK14 respectively. The drop in the strengths were about 37.52\%, 68\%, 11.42\%and 11.86\% for sample GPK1, GPK3, GPK9 and GPK11 respectively for the same. Less impact of curing temperature (within a range of $55^{\circ} \mathrm{C}$ to $85^{\circ} \mathrm{C}$ ) on sample blended with silica fume in presence of murram was indicated by the result. Similarly, the reduction in curing period had little to no effect on sample blended with silica fume and murram. A reduction in curing period from 48 hours to 24 hours (at a controlled curing temperature of $85^{\circ} \mathrm{C}$ ) imposed $7.28 \%$ and $2.95 \%$ reduction in compressive strength for sample GPK1 and GPK9 respectively. Very little changes in compressive strength were observed in the case of GPK13 and GPK14.Best result was achieved for GPK13.

\section{Scanning Electron Microscopy}

Significant change in microstructure of geopolymer paste comprising different mixture combination was exhibited by SEM analysis. The excessive presence of silica enhances the porosity due to the di-hydrogen 
produced by water. The typical volumetric increment after $10 \%$ replacement of fly ash by silica fume in the primary mix (GPK1) was found as shown in Fig.-5a (representing GPK5). The volumetric enlargement was reduced with the application of murram. For sample GPK10 comparatively compacted and less porous morphology was observed as shown in Fig.-5d The microstructure of sample GPK6 comprising of interconnected pores was observed through SEM (shown in Fig.-5c).

Table-4: Compressive Strengths of Geopolymer Paste Specimens

\begin{tabular}{|c|c|c|c|c|}
\hline \multirow[b]{2}{*}{$\begin{array}{l}\text { Sample } \\
\text { Id. }\end{array}$} & \multicolumn{4}{|c|}{ Compressive strength (MPa) after heat curing at different temperature and time } \\
\hline & $\begin{array}{l}85^{0} \mathrm{C} \text { for } \\
48 \mathrm{hrs} .\end{array}$ & $\begin{array}{c}85^{0} \mathrm{C} \text { for } \\
24 \mathrm{hrs} .\end{array}$ & $\begin{array}{c}85^{0} \mathrm{C} \text { for } \\
48 \mathrm{hrs} .\end{array}$ & $\begin{array}{l}85^{0} \mathrm{C} \text { for } \\
24 \mathrm{hrs} .\end{array}$ \\
\hline GPK1 & 27.1 & 25.1 & 16.9 & 14.2 \\
\hline GPK2 & 3.9 & 3.1 & 0.0 & 0.0 \\
\hline GPK3 & 14.3 & 11.3 & 4.6 & 4.0 \\
\hline GPK4 & - & - & - & - \\
\hline GPK5 & - & - & - & - \\
\hline GPK6 & 15.8 & 13.0 & 10.1 & 10.1 \\
\hline GPK7 & - & - & - & - \\
\hline GPK8 & 8.11 & 7.6 & 6.6 & 5.9 \\
\hline GPK9 & 34.2 & 33.1 & 30.3 & 29.2 \\
\hline GPK10 & 18.1 & 16.2 & 10.6 & 6.1 \\
\hline GPK11 & 22.5 & 21.3 & 19.9 & 17.8 \\
\hline GPK12 & 10.0 & 9.8 & 3.5 & 3.2 \\
\hline GPK13 & 39.1 & 39.0 & 36.1 & 35.9 \\
\hline GPK14 & 27.2 & 27.1 & 25.1 & 25 \\
\hline
\end{tabular}

Sometimes the presence of excessive interconnected pores is responsible for low mechanical strength in geopolymer. The micro structure of Geopolymer sample GPK10 had a better surface morphology which was suitably correlated with its attainment of maximum compressive strength. The SEM investigation depicts that better mechanical properties are the outcome of improved micro structural homogeneity. The SEM images for sample GPK11 and GPK12 are represented by Fig.-5a and Fig.-5b respectively. In these cases, the products were better in compare to GPK2 and GPK4, as cultured physically. But the presence of loose precipitates of non-reacted material in GPK12 was indicative of poor reaction. Better bonding was found for sample GPK11.In fact the level of the non-reacted material varies from specimen to specimen may be assumed to provide varying effects on their strength accordingly ${ }^{40}$. The incorporation of external silica emphasizes porous structure due to less formation of Si-O-Al-O than Si-O-Si link, which cannot be stabilized unless there is an additional source of aluminium ions. Further addition of external alumina source (murram) can better stabilize the system resulting in a far better geopolymer. Usually, for fly ash geopolymer (activated with different alkali concentration), better morphology is expected for higher alkalinity. The most interesting observation is that sample GPK4 (non-blended fly ash activated with 6\% $\mathrm{K} 2 \mathrm{O}$ ) was failed to form full or partial geopolymer structure due to the absence of Sodium Silicate in mixture whereas quite better structure was formed for sample GPK12 (fly ash blended with silica fume and murram, activated by $6 \% \mathrm{~K} 2 \mathrm{O}$ ) even at zero silicate modulus of activator. Sample GPK1 cured at different curing profile $\left(85^{\circ} \mathrm{C}\right.$ for $48 \mathrm{Hrs}$. and $55^{\circ} \mathrm{C}$ for $48 \mathrm{Hrs}$.) were cultured at very high magnification SEM images, as represented by Fig. $4 \mathrm{~b}$ and Fig. 4c. Presence of non-contributed alkali was found entrapped within the pores of sample GPK1, cured at $55^{\circ} \mathrm{C}$ for $48 \mathrm{hrs}$. Comparatively, intact structure was found for sample GPK 9 cured at $55^{\circ} \mathrm{C}$ for 48 hours, as shown in Fig. 5 d. Few micro cracks were developed due to shrinkage and that was effectively reduced by minimizing the curing duration. It is confirmed by SEM investigation that better fly ash based geopolymer structure can be formed at low alkalinity and low level of heat curing, by incorporating silica fume and murram. 
RASĀYAN $J$. Chem.

Vol. 11 | No. 3 |1018 - 1033 | July - September | 2018

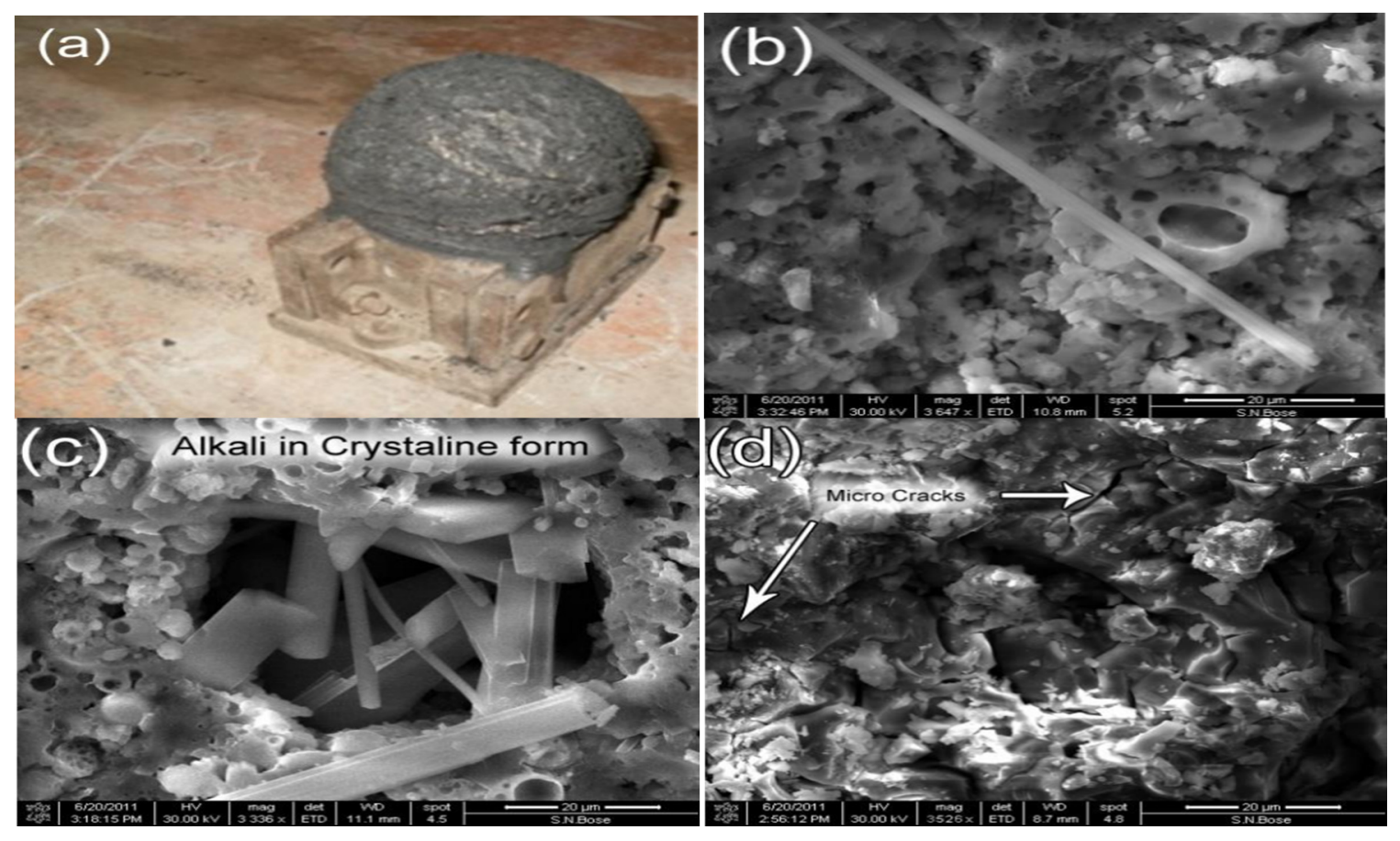

Fig.-4: (a) Sample GPK5,(b) SEM Image of GPK1 cured at $85^{\circ} \mathrm{C}$ for $48 \mathrm{hrs}$ (mag 3647x), (c) SEM Image of GPK1 cured at $55^{\circ} \mathrm{C}$ for $48 \mathrm{hrs} \mathrm{(mag} \mathrm{3336x)} \mathrm{and} \mathrm{(d)} \mathrm{SEM} \mathrm{Image} \mathrm{of} \mathrm{GPK9} \mathrm{cured} \mathrm{at} 55^{\circ} \mathrm{C}$ for 48 hours (mag 3526x)
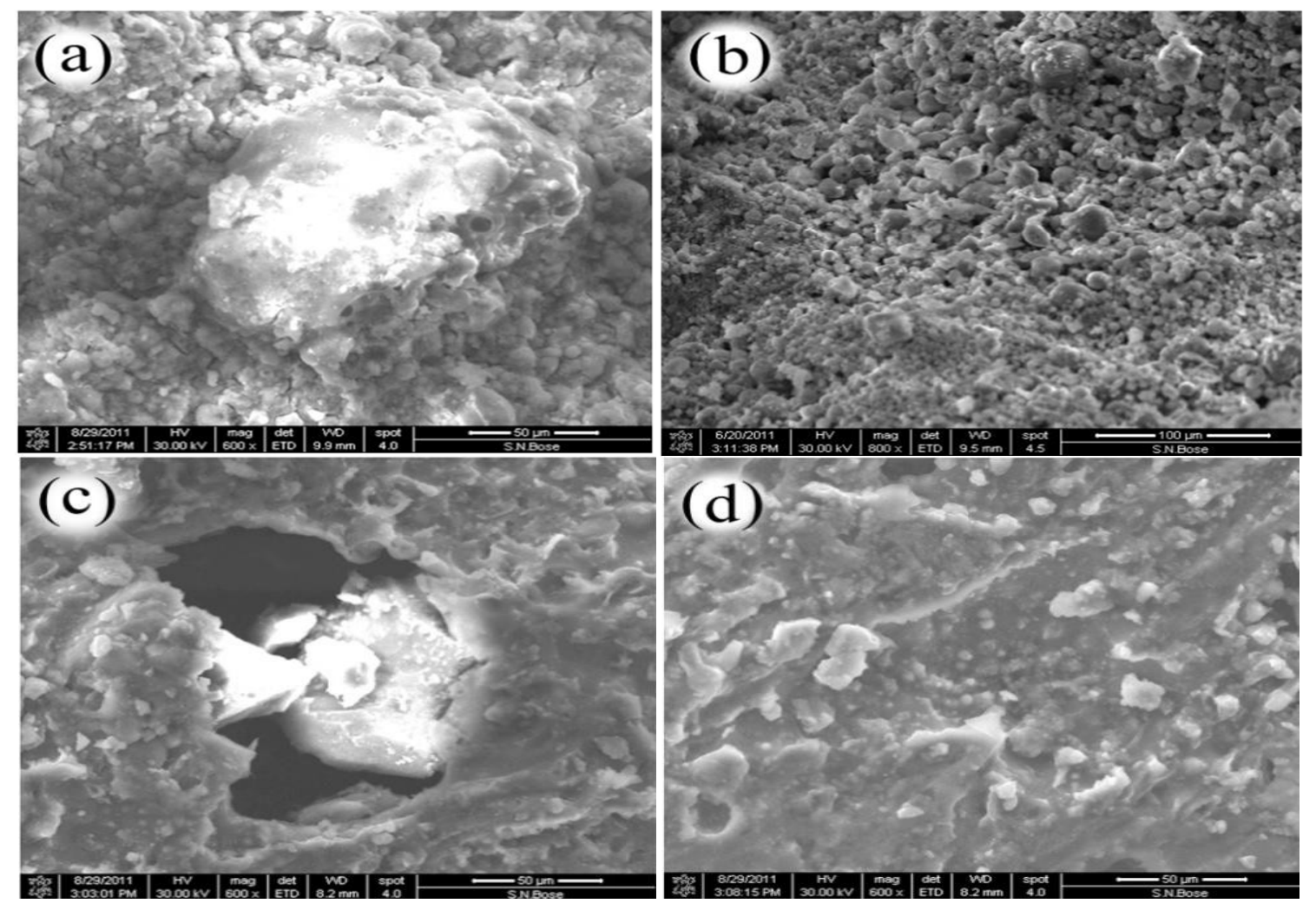

Fig.-5: SEM images of samples

(a) GPK11 (mag 600x), (b) GPK12 (mag 800x), (c) GPK6 (mag 600x), (d) GPK10 (mag 600x) 


\section{EDX (Energy Dispersive X-Ray Analysis)}

The spectrums of 4 different samples (GPK1, GPK5, GPK9 and GPK11) are shown in Figure-6 for the samples. Each result was selected from thirty individual EDX analysis. The supplementation of silica fume and murram was indicated by the peak in Silicon and Aluminium content as indicated by EDX analysis. The presence of an element like Magnesium, Calcium and Iron was found in almost every case. The greater presence of oligomers, reflecting the higher $\mathrm{Si} / \mathrm{Al}$ ratio in the reaction product was examined by EDX analysis. In sample GPK1 lower presence of reactive $\mathrm{SiO}_{2}$ was specified by the increase in $\mathrm{K} / \mathrm{Si}, \mathrm{K} / \mathrm{Al}$ ratio and a decrease in the $\mathrm{Si} / \mathrm{Al}$ ratio. The condition was opposite in GPK5 for the presence of a higher value of $\mathrm{SiO}$. With the presence of excessive reactive silicon in the form of the composed molecule, the value of $\mathrm{K} / \mathrm{Si}$ and $\mathrm{K} / \mathrm{Al}$ ratio were decreased. A higher quantity of potassium and aluminum (Fig.-6c) was exhibited by the EDX analysis of GPK9. This was because of the better stabilization of Si-O-Al due to the presence of additional aluminium acted as the charge balancer alkali cation (Potassium). A little drop in aluminium, potassium content and a corresponding rise in oxygen, silicon was observed in EDX analysis as depicted in Fig.-6d. This time lower $\mathrm{KOH}$ was indicated by the successive drop in K/Si. Better elementary distribution was observed by the analysis report of sample GPK9 that was established by the compressive strength of the sample.

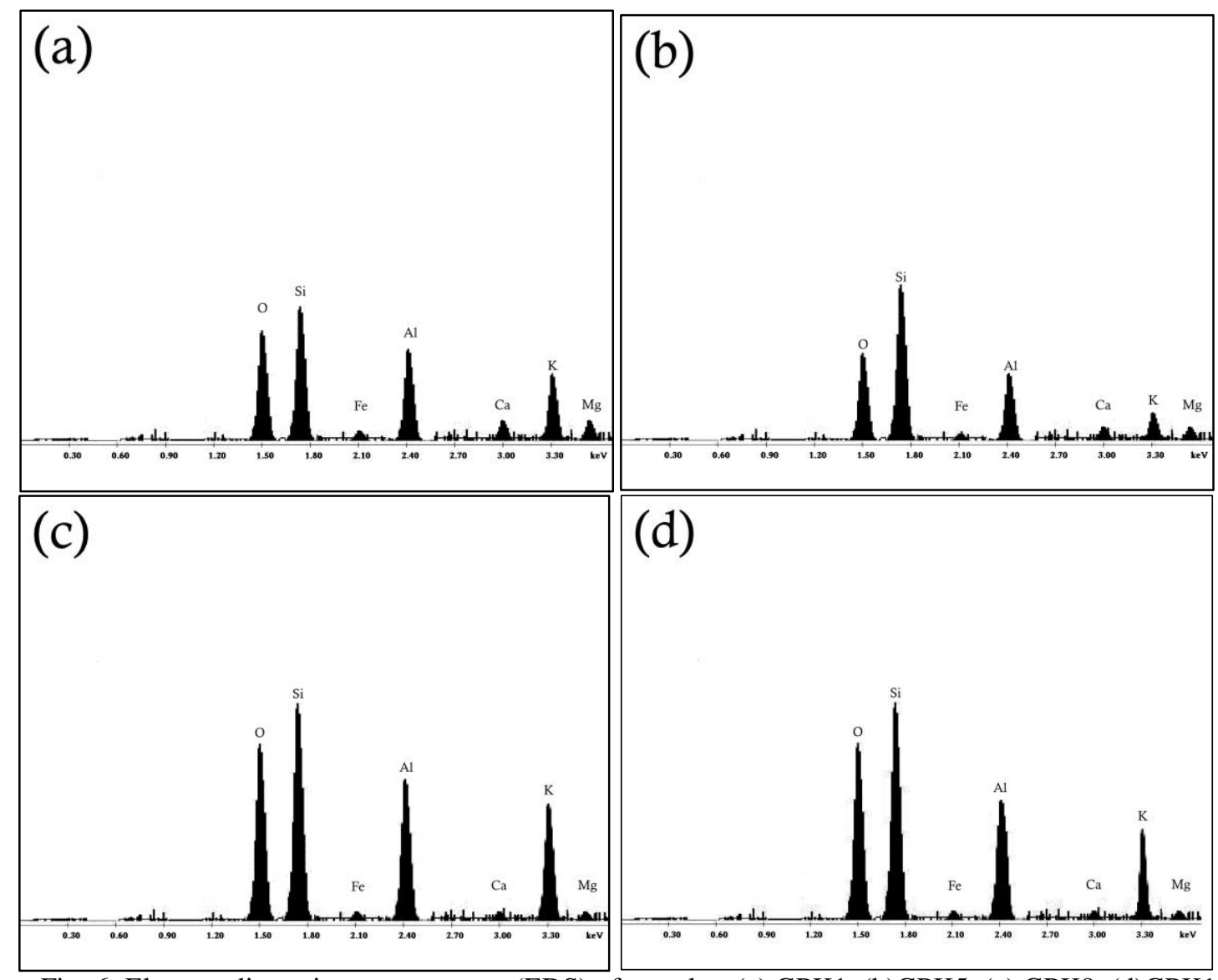

Fig.-6: Electron dispersive spectroscopy (EDS) of samples: (a) GPK1, (b)GPK5, (c) GPK9, (d)GPK1

\section{MIP of Hardened Samples}

Pore volume is affected remarkably by the replacement of fly ash with silica fume. Geopolymer sample blended with silica fume and murram provide comparatively intact structure. The replacement of fly ash by silica fume insists the rate of polymerization which in-fact enhances the evaporation of water rapidly. The geopolymer paste sample GPK 1 (Cured at $85^{\circ} \mathrm{C}$ for $48 \mathrm{hrs}$.) have a pore distribution contributing from $3.0 \mu$ to $0.009 \mu$. Sample GPK9 (Cured at $85^{\circ} \mathrm{C}$ for $48 \mathrm{hrs}$ ) allows the intrusion within a range of $5.0 \mu$ to $0.15 \mu$. Mercury intrusion porosimetry has some limitations regarding the information on the pore 
RASĀYAN J. Chem.

Vol. 11 | No. 3 |1018 - 1033 | July - September | 2018

characteristics ${ }^{41}$. In this study MIP is used to obtain perfect conclusion even within the limit in connection with porosity and pore size simultaneously. The maximum applied intrusion pressure for sample GPK1 and sample GPK9 are about 53194.551 psi and 53228.703 psi respectively. In this test, pore volume distribution represents a function $\mathrm{F}$ equal to $-\mathrm{dV} / \mathrm{d} \log \mathrm{D}$. Here, $\mathrm{V}$ equal to the combined pore capacity. In Fig.-7 pore volume distribution function is plotted with pore diameter for sample GPK1 and GPK9. The geopolymer sample GPK1 shows significant intrusion within a diameter, range of 5 micrometres to 0.2 micrometer and maximum peak intrusion appears at 2 micrometres. The sample GPK9 gives prominent intrusion within a range of 2 micrometer to 0.009 micrometer and the maximum peak has been attended at 0.075 micrometer. This phenomenon clearly indicates the drop in average pore size for the sample GPK9. Fig.-8 and Fig.-9 show noticeable difference in the pressure responsible for the sudden change in delta volume. At a pressure of $398.638 \mathrm{psi}$ a sudden increment in delta volume $(0.0228 \mathrm{cc} / \mathrm{g})$ occurs for sample GPK9 whereas a sudden increment of delta volume $(0.0326 \mathrm{cc} / \mathrm{g})$ has been observed for sample GPK1 at a pressure of 93.746 psi. The pore diameters responsible for the sudden change in delta volume are 2.276 micrometer and 0.535 micrometer for sample GPK1 and GPK9 respectively. In both the cases, the hysteresis loop between the intrusion and extrusion are visible which indicates the amount of fluid unable to extrude. It is found that the mode of extrusion curve has been discontinued for sample GPK1 which is basically due to the breaking of the specimen for excessive internal pressure. Physically it can be explained that the bottle neck shape of pores allows the smoother intrusion but restricts the extrusion in the same way. Though the range of pores responsible for intrusion is quite larger in case of sample GPK9, but it happens comparatively at a higher intensity of pressure. It is noticeable that around $41.85 \%$ and $87.67 \%$ volume are intruded at a pressure of 1022.157 psi for sample GPK9 and 943.212 psi for sample GPK1 respectively. This depicts that percent volume intrusion is almost twice for sample GPK1 in compare to sample GPK9 even at same pressure intensity. Parallel to that smoother extrusion curve indicates no breakage of sample GPK9 which supports the strong integrity of the structure.
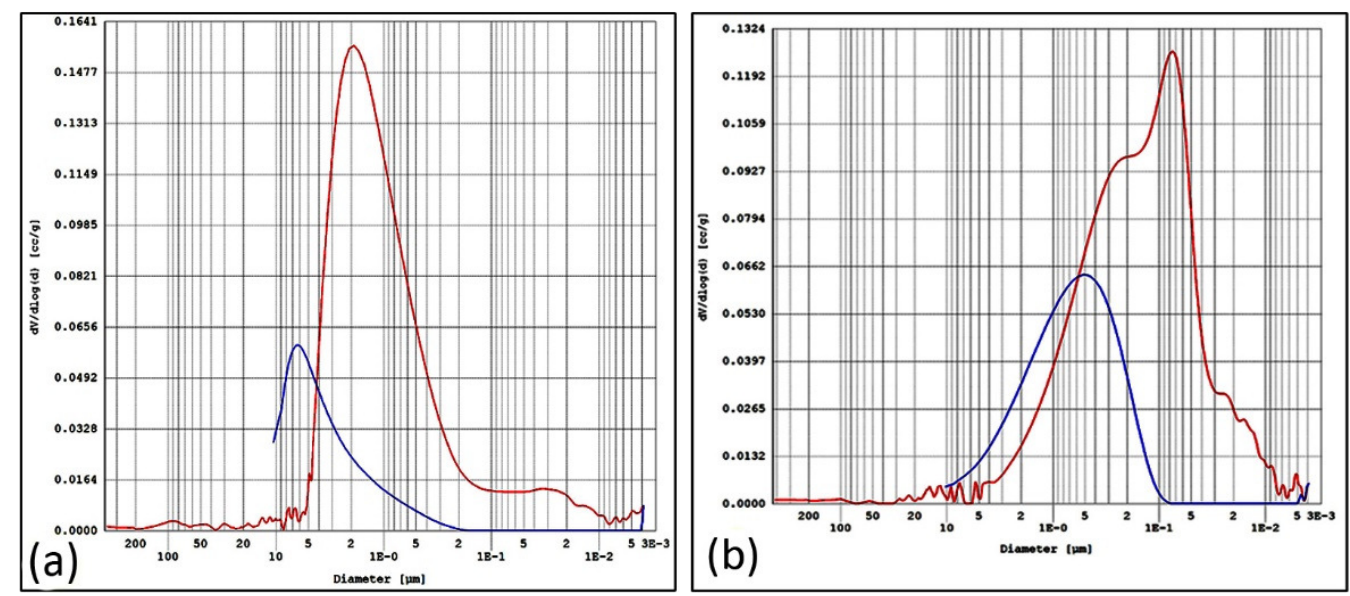

Fig.-7: MIP distribution curve of samples (a) GPK1 and (b) GPK9

\section{CONCLUSION}

A detailed micro-structural study and a comparative performance analysis have been performed for the developed blended geopolymer paste by replacing fly ash with fume silica and murram in the present experimental study.

The major findings of this papers are as follows:

- Murram as a tertiary input in silica fume blended fly ash improves the mechanical properties of the geopolymers. Although the addition of only silica fume reduces the mechanical properties of geopolymer due to the lesser formation of three-dimensional geopolymeric aluminosilicate network, the effect of silica fume is found to be favorable in the presence of murram. In its presence, silica fume is likely to result in initial polymerization even in absence of sodium silicate. 
- Moreover, higher consistency is quantified for samples blended with silica fume even at lower water content and lower alkalinity. Geopolymer samples blended with silica fume and murram exhibit better performance.

- The presence of the extra alkaline solution in fly ash based geopolymer caused by partial dissolution of the fly ash spheres is found to be absent for samples blended with silica fume and murram. This reflects the increment in dissolution rate of fly ash, which is favorable in the reduction of efflorescence.

- A high strength geopolymer with high workability was successfully made even at lower water content and lower curing heat consumption.

- Rising of curing temperature and duration have little to no effect on the strength of blended geopolymer in the presence of silica fume \& murram. It may be because of the silica fume and murram which introduce acceleration to the rate of polymerization with a reduced external parameter.

- The inception data of the intruded volume pore sizes and corresponding pressure indicate better microstructure of y ash based geopolymer blended with silica fume and murram.

- It is found that the coexistence of silica fume and murram in a moderate amount is responsible for the better strength, consistency, micro-structure for every case, even at lower alkalinity, lesser water content and lesser heat energy consumption.

The present research was inclined towards the development of sustainable construction materials by utilizing environmental outcomes (called disposals) to take a step further towards a greener environment. The authors are currently focussing on the development of fly ash based geopolymer activated with naturally available alkali like sludge etc. The effect of different acids and salts of different concentration on blended geopolymer are currently being evaluated.

Prolonged microstructural study on blended and non-blended fly ash Geopolymer with time and its impact on strength and stability are the future scopes of this study. Evaluation of the economic stand of the blended fly ash based geopolymer should also be justified in future.

\section{REFERENCES}

1. D. N. Huntzinger and T. D. Eatmon, J. Clean Prod., 17(7), 668(2009), DOI: 10.1016/j.jclepro.2008.04.007

2. V. M. Malhotra and P. K. Mehta, High-Performance, High-Volume Fly Ash Concrete: Materials, Mixture Proportioning, Properties, Construction Practice, and Case Histories, Supplementary Cementing Materials for Sustainable Development Inc., Ottawa, p. 1-124 (2005).

3. R.A. Feely, C. L. Sabine et al., Science, 305, 362(2004), DOI: 10.1126/science.1097329

4. P. K. Mehta and R.W. Burrows, ICJ, 75(7), 437(2001), DOI:10.1.1.475.5570

5. A. Castel and S. J. Foster, Cem. Concr. Res., 72, 48(2015), DOI:10.1016/j.cemconres.2015.02.016

6. N Ganesan and et al., Constr. Build. Mater., 73, 326(2014), DOI: 10.1016/j.conbuildmat.2014.09.092

7. M. Mohammadreza and K. A. Riding, Cem. Concr. Comp., 56,95(2015), DOI: 10.1016/j.cemconcomp.2014.10.004

8. A. Nadeem, S. Ali Memon, and T. Yiu Lo, Constr. Build. Mater., 38, 338(2013), DOI: 10.1016/j.conbuildmat.2012.08.042

9. Mehta, P. Kumar, High-performance, Proceedings of the international workshop on sustainable development and concrete technology. Ames, IA, Iowa State University, May 20-21, 03, (2004).

10. J. Temuujin, R. P.Williams, and A.V. Riessen, J. Mater. Process. Technol., 209(12-13), 5276(2009), DOI: $10.1016 / j . j m a t p r o t e c .2009 .03 .016$

11. P. Sarker, R. Haque, and K.V. Ramgolam, Mater. Des., 44, 580(2013), DOI: 10.1016/j.matdes.2012.08.005

12. K. Somna, C. Jaturapitakkul, P. Kajitvichyanukul, P. Chindaprasirt and et al., Fuel, 90(6), 2118(2011), DOI: 10.1016/j.fuel.2011.01.018

13. P. Chindaprasirt, P. Paisitsrisawat and U. Rattanasak, Adv. Powder Technol., 25(3), 1087(2014), DOI :10.1016/j.apt.2014.02.007

14. N. K. Lee, G. H. An, K.T. Koh and G. S. Ryu, Adv. Mater. Sci. Eng., 2016, Article ID 2192053(2016), DOI:10.1155/2016/2192053 
RASĀYAN J. Chem.

Vol. 11 | No. 3 |1018 - 1033 | July - September | 2018

15. Okoye, N. Francis, S. Prakash, and N. B. Singh, J. Clean. Prod., 149, 1062(2017), DOI:10.1016/j.jclepro.2017.02.176

16. P. Duan, C. Yan, and W. Zhou, Cem. Concr. Comp., 78, 108(2017), DOI: 10.1016/j.cemconcomp.2017.01.009

17. K. Kohno, In Proceedings of the third international conference on the use of fly ash, silica fume, slag and natural pozzolans in concrete, Trondheim, Norway, 1989, American Concrete Institute Publication SP-114, 815826, (1989),

18. H. Cheng-Yi, R. F. Feldman, Cem. Concr. Comp., 15, 585592 (1985), DOI:10.1016/00088846(85)90056-0

19. J. Davidovits, Geopolymer Chemistry and Applications, Geopolymer Institute (2008).

20. H. Xu, J. S. J. Van Deventer, Int. J. Miner. Process., 59(3), 247(2000), DOI:10.1016/S03017516(99)00074-5

21. A. Kumar and S. Kumar, Constr. Build. Mater., 38, 865(2013), DOI: 10.1016/j.conbuildmat.2012.09.013

22. Ye Nan and et al., J. Am. Ceram. Soc., 97(5), 1652(2014), DOI:10.1111/jace.12840

23. Mo. Zhang and et al., Fuel 134, 315(2014), DOI: 10.1016/j.fuel.2014.05.058

24. M. W. Grutzeck, D.D. Siemer, J. Am. Ceram. Soc., 80(9), 24492458 (1997), DOI:10.1111/j.11512916.1997.

25. D. Khale and R. Chaudhary, J. Mater. Sci., 42(3), 729-746 (2007), DOI:10.1007/s10853-006-0401-4

26. E. Prudhomme and et al., J. Eur. Ceram. Soc., 30, 1641(2010), DOI: 10.1016/j.jeurceramsoc.2010.01.014

27. Kirschner, Andrea, Harald Harmuth, Ceram. Silik., 48 (3), 117(2004)

28. S. Thokchom, P. Ghosh and S. Ghosh, J. Civ. Eng. Manag., 17 (3), 393(2011), DOI :10.3846/13923730.2011.594225

29. A. Palomo, M. W. Grutzeck and M. T. Blanco, Cem. Concr. Res., 29(8), 1323(1999), DOI:10.1016/S0008-8846(98)00243-9

30. J.T. Gourley, conference on adaptive materials for a modern society, Sydney, Institute of materials engineering Australia, 49 (15-26), 1455(2003).

31. D. Dutta, S. Chakrabarty, C. Bose, S. Ghosh, STM Journals, 2, 1(2012).

32. D. Dutta, S. Ghosh, Adv. Civ. Eng., 12, 2940169 (2018), DOI:10.1155/2018/2940169

33. P. Duxson, A. Fernandez-Jimenez, J.L. Provis, G.C. Lukey, A. Palomo, J.S.J. van Deventer, J. Mater. Sci., 42, 2917(2007), DOI:10.1007/s10853-006-0637

34. E. Obonyo, E. Kamseu, U. C. Melo, C. Leonelli, Sustainability, 3(2), 410(2011), DOI:10.3390/su3020410

35. Mohd. N. Qureshi and S. Ghosh, Adv. Civ. Eng. Mater., 2 (1), 62(2013), DOI: 10.1520/ACEM20120029.

36. F. A. Memon, M.F. Nuruddin, N. Shafiq, Int. J. Min. Met. Mater., 20 (2), 205(2013), DOI: 10.1007/s12613-013-0714-7.

37. J. J. Brooks, ACI Mater. J., 99 (6), 591(2002).

38. J.G.S. Van Jaarsveld, J.S.J. Van Deventer and G.C. Lukey, Chem. Eng. J., 89(1-3), 63(2002), DOI: 10.1016/s1385-8947(02)00025-6.

39. D. Dutta, S. Ghosh, Cur. Adv. Civ. Eng. (CACE), American V-King Scientific Publishing, 2(3), 96 (2014).

40. P. Duxson, J. L. Provis, G. C. Lukey, S. W. Mallicoat, W. M. Kriven and J. S.J. van Deventer, Colloids Surf. A. Physicochem. Eng. Asp., 269(1-3), 4758 (2005), DOI: 10.1016/j.colsurfa.2005.06.060.

41. J. Van Brakel, Powder Tech., 29, 201(1981).

42. K. Ghosh and P. Ghosh, Rasayan J.Chem., 11(1), 426(2018), DOI: 10.7324/RJC.2018.1112036

[RJC-3046/2018] 